\title{
Differentially Expressed Genes in Two LNCaP Prostate Cancer Cell Lines Reflecting Changes during Prostate Cancer Progression
}

\author{
Markku H. Vaarala, Katja Porvari, Atte Kyllönen, and Pirkko Vihko \\ Biocenter Oulu (MHV, KP, PV), World Health Organization Collaborating Centre for Research on Reproductive \\ Health, and Department of Pathology (AK), University of Oulu, Oulu; and World Health Organization Collaborating \\ Centre for Research on Reproductive Health (PV), Department of Biosciences, Division of Biochemistry, University \\ of Helsinki, Helsinki, Finland
}

\begin{abstract}
SUMMARY: Prostate cancer tends to become transformed to androgen-independent disease over time when treated by androgen-deprivation therapy. We used two variants of the human prostate cancer cell line LNCaP to study gene expression differences during prostate cancer progression to androgen-independent disease. Production of prostate-specific antigen was regarded as a marker of androgen-dependence and loss of prostate-specific antigen was regarded as a marker of androgenindependence. mRNA from both cell lines was used for cDNA microarray screening. Differential expression of several genes was confirmed by Northern blotting. Monoamine oxidase A, an Expressed Sequence Tag (EST) similar to rat P044, and EST AA412049 were highly overexpressed in androgen-dependent LNCaP cells. Tissue-type plasminogen activator, interferon-inducible protein p78 (MxB), an EST similar to galectin-1, follistatin, fatty acid-binding protein 5, EST AA609749, annexin I, the interferon-inducible gene 1-8U, and phospholipase D1 were highly overexpressed in androgen-independent LNCaP cells. All studied genes had low or no expression in PC-3 cells. The EST similar to rat P044, the EST similar to galectin-1, follistatin, annexin I, and the interferon-inducible gene 1-8U were also expressed in benign prostatic hyperplasia tissue. The Y-linked ribosomal protein S4, Mat-8, and EST AA307912 were highly expressed in benign prostatic hyperplasia tissue. Additionally, both confirmation of differential expression in Northern blots and in situ hybridization were carried out for monoamine oxidase A, the EST similar to rat P044, the EST similar to galectin-1, fatty acid-binding protein 5 , and the interferon-inducible gene 1-8U. We identified several potential prostate cancer markers, indicating that the method used is a useful tool for the screening of cancer markers, but other methods, such as in situ hybridization, are needed to further investigate the observations. (Lab Invest 2000, 80:1259-1268).
\end{abstract}

\begin{abstract}
$P^{r \sin t a n}$ rostate cancer is the most commonly diagnosed cancer among men in Western industrialized countries. The growth of prostate cancer is usually androgendependent at the beginning, but tends to become transformed to androgen-independent disease over time when treated by androgen-deprivation therapy (Schroder, 1998). The transition from hormone-dependent to hormone-independent tumorigenesis is believed to be a consequence of multiple genetic alterations. This multistep process is thought to include a cascade of genetic alterations caused by activation of oncogenes and/or inactivation of tumor suppressor genes (Fearon and Vogelstein, 1990; Knudson, 1993). A widely used in vitro model of prostate cancer is the LNCaP cell line (Horoszewicz et al, 1980). Androgens are essential for growth of LNCaP cells, unless they have become transformed to androgen-independent clones (van Steen-
\end{abstract}

Received March 20, 2000.

Grants provided by Research Council for Health, Academy of Finland (3314 and 40990); and the Ministries of Education, Social Affairs and Health, and Foreign Affairs, Finland; Finnish Cancer Foundation.

Address reprint requests to: Dr. P. Vihko, WHO CCR, P.O. Box 5000, FIN-90014 University of Oulu, Finland. Fax: 3588315 5631; E-mail: pvihko@whoccr.oulu.fi brugge et al, 1991). Androgen-dependent and androgen-independent LNCaP cell lines have previously been used for studying differentially expressed genes in the respective stages of prostate carcinoma. B cell translocation gene 1, the UDP glucuronosyl transferase gene 2B15, and two unknown genes are differentially expressed (Chang et al, 1997). The cell lines used expressed both prostate-specific antigen (PSA) and prostatic acid phosphatase and contained androgen receptors (although one cell line was androgenindependent). Differential expression of fibronectin, E2 ubiquitin-conjugating enzyme, metalloproteinaserelated collagenase, and breast basic conserved gene was shown in another androgen-independent LNCaP cell line in a study by Stubbs et al, 1999. Recently, differential display analysis was successfully used for identification of a cDNA (DD3) with prostate cancerspecific expression (Bussemakers et al, 1999).

To study gene expression changes during prostate cancer progression, we used two LNCaP cell line variants. Loss of PSA production in $\mathrm{LNCaP}$ cells was regarded as a marker of androgen-independent growth of the cells. The non-PSA-producing LNCaP cell line $(\mathrm{LNCaP}-)$ served as a model of progressive prostate cancer, whereas the PSA-producing LNCaP 
cell line $(\mathrm{LNCaP}+)$ served as a model of welldifferentiated prostate cancer. The aim of this study was to identify differentially expressed genes in LN$\mathrm{CaP}+/-$ cells using cDNA array technology. With this technology, the expression of several thousand genes can be observed in single hybridization screening. Thus, this technology is a powerful tool in cancer research with potential for the identification of new cancer markers. Several genes with prominent expression in one of the cell line variants were analyzed by Northern blot hybridization in the $\mathrm{LNCaP}+/-$, PC-3, and DU-145 cell lines and in benign prostatic hyperplasia (BPH) tissue, and some promising markers were investigated by in situ hybridization (ISH).

\section{Results}

\section{Overview of the Screening Results}

In gene expression microarray analysis, 7075 human cDNAs were screened. Among genes expressed at high levels in both LNCaP cell lines there were several genes known to take part in the regulation of cell growth, apoptosis, or oncogene action. These genes are presented in Table 1. Many genes were expressed at low level: signal values below 200 (range: 76 to 199) were detected for 2013 genes. Of these genes, 1252 $(62 \%)$ were EST (Expressed Sequence Tags) with no homology to known sequences; 207 (10\%) were EST with similarity to some known sequences; and 554 (28\%) were known clones different from EST.

\section{Differentially Expressed Genes}

The genes expressed most prominently in LNCaP+ and LNCaP - cells are presented in Tables 2 and 3, respectively. Androgen receptor was expressed in $\mathrm{LNCaP}+$ cells with a signal value of 2941, 7.9 times overexpressed in these cells (Table 2 ). The respective value in LNCaP - cells was 373 , indicating the presence of androgen receptor transcripts in these cells as well.

In $\mathrm{LNCaP}+$ cells, the genes for four serine proteases, PSA (Accession number (AC): M24543), prostate-specific glandular kallikrein (hK2, AC: S39329), TMPRSS2 (AC:

Table 1. Oncogenes, Genes Related to Regulation of Oncogene Action, Cell Growth or Apoptosis Expressed at High Level in Both LNCaP+ and LNCaP- Cells

\begin{tabular}{ccll}
\hline $\begin{array}{c}\text { Signal } \\
\text { Value in } \\
\text { LNCaP+ }\end{array}$ & $\begin{array}{c}\text { Signal } \\
\text { Value in } \\
\text { LNCaP- }\end{array}$ & \multicolumn{1}{c}{ Gene Name } & \\
\hline 8489 & 7057 & RAB7, member of RAS oncogene-like family 1 & Accession \\
6675 & 5689 & Synovial sarcoma, translocated to X chromosome & D844888 \\
4631 & 7110 & RAN, member RAS oncogene family & X79201 \\
5527 & 5198 & CASP8 and FADD-like apoptosis regulator & AF052578 \\
6742 & 3934 & Human mRNA for hepatoma-derived growth factor & AF015450 \\
6871 & 3324 & Myeloid leukemia factor 2 & Al720570 \\
5463 & 4643 & V-crk avian sarcoma virus CT10 oncogene homolog & AF070539 \\
3905 & 4692 & RAB interacting factor & D10656 \\
2437 & 5575 & non-metastatic cells 1, protein (NM23A) & U74324 \\
3754 & 3801 & Mutated in colorectal cancers & AA399275 \\
4115 & 3391 & Proliferation-associated 2G4, 38kD & M62397 \\
2404 & 4699 & Proliferation-associated gene A & U59435 \\
3473 & 3468 & Teratocarcinoma-derived growth factor 1 & X67951 \\
3380 & 3368 & Caspase 10, apoptosis-related cysteine protease & M96955 \\
3800 & 2869 & tumor protein D52 & U60519 \\
3676 & 2991 & V-myc avian myelocytomatosis viral oncogene homolog & U18914 \\
3474 & 3144 & mouse double minute 4; p53-binding protein & V00568 \\
3368 & 3207 & ras homolog gene family, member G (rho G) & AF007111 \\
4221 & 2316 & G1 to S phase transition 1 & X61587 \\
2735 & 3684 & Defender against cell death 1 & U95742 \\
3260 & 3132 & Caspase 6, apoptosis-related cysteine protease & U84214 \\
2099 & 4244 & Human transformation-sensitive protein & U20536 \\
2285 & 3977 & SHC (Src homology 2 domain-containing) transforming protein 1 & M86752 \\
2682 & 3247 & V-raf-1 murine leukemia viral oncogene homolog 1 & X68148 \\
3193 & 2646 & Proliferating cell nuclear antigen & X03484 \\
3074 & 2710 & Neuronal apoptosis inhibitory protein & Al631255 \\
2922 & 2620 & Forkhead (Drosophila) homolog (rhabdomyosarcoma)-like 1 & U80017 \\
2583 & 2622 & Ewing sarcoma breakpoint region 1 & AF032886 \\
2031 & 2374 & V-crk avian sarcoma virus CT10 oncogene homolog-like & Y07848 \\
2014 & 2011 & RAB13, member RAS oncogene family & X59656 \\
\hline & & X75593 & \\
\hline
\end{tabular}

Signal values (arbitrary units), gene identification, and accession number are presented in descending order of total signal values. 
Table 2. Genes Overexpressed in LNCaP+ Cells

\begin{tabular}{|c|c|c|c|c|}
\hline Overexpression & $\begin{array}{c}\text { Signal } \\
\text { Value in } \\
\text { LNCaP+ }\end{array}$ & $\begin{array}{c}\text { Signal } \\
\text { Value in } \\
\text { LNCaP- }\end{array}$ & Gene Name & Accession \\
\hline 105.1 & 26165 & 249 & Kallikrein 3 (prostate specific antigen, PSA) & M24543 \\
\hline 49.3 & 20147 & 409 & Kallikrein 2, prostatic (hK2) & S39329 \\
\hline 22.9 & 3342 & 146 & Transmembrane protease, serine 2 (TMPRSS2) & U75329 \\
\hline 20.8 & 7984 & 384 & Monoamine oxidase $\mathrm{A}(\mathrm{MAOA})$ & M69226 \\
\hline 15.6 & 4962 & 319 & Myosin VI (MY06) & AB002387 \\
\hline 14.7 & 1838 & 125 & Epithelial V-like antigen & Al819274 \\
\hline 13.4 & 2526 & 188 & Desmoplakin (DPI, DPII) & M77830 \\
\hline 12.6 & 2148 & 171 & EST & AA412049 \\
\hline 12.2 & 3010 & 247 & Phospholemman-like (Mat-8) & AA826766 \\
\hline 11.8 & 1325 & 112 & EST & N51335 \\
\hline 11.3 & 4239 & 376 & Catenin alpha 1 (102 kD) & AF102803 \\
\hline 10.6 & 8086 & 764 & Ribosomal protein S4, Y-linked (RPS4Y) & Al929331 \\
\hline 9.9 & 2835 & 287 & Selenium-binding protein 1 & U29091 \\
\hline 8.7 & 5864 & 675 & Protein phosphatase 3 catalytic subunit (PPP3CA) & AA504039 \\
\hline 8.6 & 1063 & 124 & EST & AA781244 \\
\hline 8.5 & 2550 & 299 & Protein kinase, cAMP-dependent, catalytic, beta & M34181 \\
\hline 8.5 & 2266 & 268 & Cyclin-dependent kinase inhibitor 1A (p21, Cip1) & L25610 \\
\hline 8.3 & 5213 & 629 & Creatine kinase, mitochondrial 1 & J04469 \\
\hline 8.1 & 2181 & 269 & 3-oxoacid CoA transferase & U62961 \\
\hline 7.9 & 2941 & 373 & Androgen receptor & M27430 \\
\hline 7.7 & 1333 & 174 & Islet cell autoantigen 1 (69 kD) & U26591 \\
\hline 7.0 & 1379 & 198 & T-cell receptor, gamma cluster & M16768 \\
\hline 6.8 & 1347 & 197 & H. sapiens gene from PAC 295C6, similar to rat P044 & Al92351 \\
\hline 6.8 & 1652 & 243 & Hexosaminidase A (alpha polypeptide) & S62076 \\
\hline 6.4 & 7972 & 1241 & Caldesmon 1 & M64110 \\
\hline 6.3 & 2177 & 343 & EST & Al536671 \\
\hline 5.9 & 874 & 148 & EST & AA641953 \\
\hline 5.7 & 1102 & 194 & Kallikrein 1, renal/pancreas/salivary & M12706 \\
\hline
\end{tabular}

Overexpression, signal values (arbitrary units) in $\mathrm{LNCaP}+/-$, gene identification and respective accession number are presented in descending order of overexpression.

U75329), and kallikrein 1 (AC: M12706), were among the thirty most overexpressed genes, whereas in LNCaPcells there was only one serine protease, trypsin 3 (AC: $\mathrm{X} 71345)$, among the ninety most overexpressed genes. Furthermore, genes for three transmembrane proteins, TMPRSS2, Mat-8 (AC: AA826766) and nma (AC: U23070), were among the ninety most overexpressed genes in $\mathrm{LNCaP}+$ cells. In $\mathrm{LNCaP}-$ cells, there were several interferon-inducible genes that were overexpressed. Among the ninety most overexpressed genes were cDNAs for $2^{\prime}-5$ ' oligoadenylate synthetase 2 (OAS2, AC: M87284), MxA (AC: M30817), interferon-inducible protein 17 (AC: AA428847), a $56 \mathrm{kDa}$ protein (AC: X03557), interferon- $\alpha$ inducible protein 27 (AC: AA302123), interferon- $\gamma$-inducible protein 16 (AC: S75433), MxB (AC: M33883), and the interferon-inducible gene 1-8U (AC: X57352). Protein phosphatase 3 and myosin VI were differentially expressed in the whole array, but they were expressed at comparable levels in both $\mathrm{LNCaP}+$ and $\mathrm{LNCaP}$ - cells according to the results of Northern blotting (data not shown).

\section{Analysis of Overexpressed Genes in LNCaP+ Cells}

The Y-linked ribosomal protein S4 was expressed strongly in BPH tissue, was expressed at lower levels in $\mathrm{LNCaP}+$, and was hardly detectable in PC-3 or LNCaP - cells (Table 4, Fig. 1a). Monoamine oxidase A (MAOA) was expressed in LNCaP+ cells and at lower levels in BPH tissue and LNCaPcells (Table 4, Fig. 1a), and was not seen in PC-3 cells. ISH showed the localization of MAOA transcripts in both benign and malignant epithelium (Fig. 2 , a and b). Mat- 8 was expressed in BPH tissue and in $\mathrm{LNCaP}+$ cells, whereas transcripts encoding Mat-8 were absent in $\mathrm{PC}-3$ and $\mathrm{LNCaP}-$ cells (Table 4, Fig. 1a). An mRNA for an EST similar to rat P044 was most prominently expressed in LNCaP+ cells and $\mathrm{BPH}$ tissue, and was weakly expressed in LNCaP - cells (Table 4, Fig. 1a). It was expressed at a low level in ISH, but was detectable in benign and malignant epithelia (Fig. 2, c and d). ISH showed that EST AA781244 was expressed at similar levels in benign and malignant epithelia (Fig. 2, e and f). EST AA781244 was weakly expressed in LNCaP+ cells and BPH tissue in Northern blots (Table 4). The gene encoding EST AA412049 was expressed only in LNCaP + cells in Northern blots (Table 4), but in ISH it was detectable in both benign and malignant epithelia (Fig. 2, g and h). 
Table 3. Genes Overexpressed in LNCaP- Cells

\begin{tabular}{|c|c|c|c|c|}
\hline Overexpression & $\begin{array}{c}\text { Signal } \\
\text { Value in } \\
\text { LNCaP- }\end{array}$ & $\begin{array}{c}\text { Signal } \\
\text { Value in } \\
\text { LNCaP+ }\end{array}$ & Gene Name & Accession \\
\hline 40.9 & 18986 & 464 & Plasminogen activator, tissue (tPA) & D01096 \\
\hline 34.6 & 6461 & 187 & $2-5 \mathrm{~A}$ synthetase 2 (OAS2) & M87284 \\
\hline 34.2 & 8345 & 244 & Myxovirus resistance 1 (interferon-inducible protein p78) & M30817 \\
\hline 25.9 & 7567 & 292 & ESTs, Moderately similar to GALECTIN-1 & AA340061 \\
\hline 25.1 & 4262 & 170 & Phospholipase D1, phosphatidylcholine-specific (PLD1) & U38545 \\
\hline 21.0 & 3672 & 175 & Follistatin & M19481 \\
\hline 21.0 & 7675 & 366 & Interferon-induced protein 17 & AA428847 \\
\hline 20.9 & 3623 & 173 & Homo sapiens clone 23916 mRNA sequence & AF035283 \\
\hline 19.0 & 4119 & 217 & Human mRNA for $56-\mathrm{KDa}$ protein induced by interferon & X03557 \\
\hline 18.2 & 4284 & 235 & Annexin I (lipocortin I) & X05908 \\
\hline 18.0 & 2735 & 152 & SH3-domain GRB2-like 2 & AF036268 \\
\hline 17.6 & 2693 & 153 & Human mRNA for unknown product, partial cds & D29810 \\
\hline 17.6 & 4513 & 257 & Cytochrome P450, subfamily XXVIIB & AB006987 \\
\hline 16.5 & 3545 & 215 & EST & Al352370 \\
\hline 15.8 & 4838 & 307 & EST & AA307912 \\
\hline 15.1 & 2308 & 153 & EST & Al809937 \\
\hline 14.9 & 3606 & 242 & Fatty acid-binding protein 5 (psoriasis-associated) (FABP5) & AA888264 \\
\hline 14.7 & 3664 & 250 & Defensin, alpha 1, myeloid-related sequence & M26602 \\
\hline 14.4 & 9620 & 669 & Human butyrophilin (BTF1) mRNA, complete cds & U90543 \\
\hline 13.6 & 2448 & 180 & Human enkephalin B (enkB) gene & AL034562 \\
\hline 13.6 & 2471 & 182 & Interferon, alpha-inducible protein 27 & AA302123 \\
\hline 12.9 & 2307 & 179 & Human chromosome 16 BAC clone CIT987SK-A-101F10 & AC002550 \\
\hline 12.8 & 4510 & 351 & Heparin-binding growth factor-binding protein & M60047 \\
\hline 12.8 & 3964 & 309 & Protease, serine, 3 (trypsin 3) & X71345 \\
\hline 12.7 & 1761 & 139 & EST & Al422824 \\
\hline 12.1 & 2950 & 243 & TNF receptor-associated factor 3 & U19260 \\
\hline 11.9 & 2389 & 201 & Tumor necrosis factor receptor superfamily, member 8 & D86042 \\
\hline 11.9 & 4253 & 358 & Activin A receptor, type I & L02911 \\
\hline
\end{tabular}

Overexpression, signal values (arbitrary units) in $\mathrm{LNCaP}+/-$, gene identification and respective accession number are presented in descending order of overexpression.

Table 4. Semi-Quantitative Analysis of Genes Overexpressed in LNCaP+/- Cells

\begin{tabular}{|c|c|c|c|c|}
\hline Gene Name & LNCaP+ & LNCaP- & $\mathrm{BPH}$ & PC-3 \\
\hline Ribosomal protein S4, Y-linked & + & $(+)$ & +++ & $(+)$ \\
\hline Monoamine oxidase $\mathrm{A}$ & +++++ & $(+)$ & + & - \\
\hline Mat-8 & + & - & +++ & - \\
\hline EST similar to rat P044 & +++ & $(+)$ & ++ & - \\
\hline EST AA781244 & + & - & + & - \\
\hline EST AA412049 & +++ & - & - & - \\
\hline Plasminogen activator, tissue type & - & +++ & - & - \\
\hline $\mathrm{MxB}$ & - & +++ & - & - \\
\hline EST AA307912 & - & + & +++ & + \\
\hline EST similar to galectin-1 & - & +++ & ++ & + \\
\hline Follistatin & - & +++ & ++ & + \\
\hline Fatty acid-binding protein 5 & - & ++ & - & + \\
\hline EST AA609749 & - & +++ & + & $(+)$ \\
\hline Annexin I & - & ++ & +++ & $(+)$ \\
\hline Interferon-inducible gene 1-8U & - & +++ & ++++ & - \\
\hline Phospholipase D1 & - & +++ & - & $(+)$ \\
\hline
\end{tabular}

Intensities of hybridization signals for different mRNAs obtained by Northern blot analysis were quantified by densitometric scanning and normalized against signals obtained for GAPD. Northern blots with LNCaP+/- cell, BPH tissue and PC-3 cell mRNAs were used. Expression levels of different genes are not comparable. 


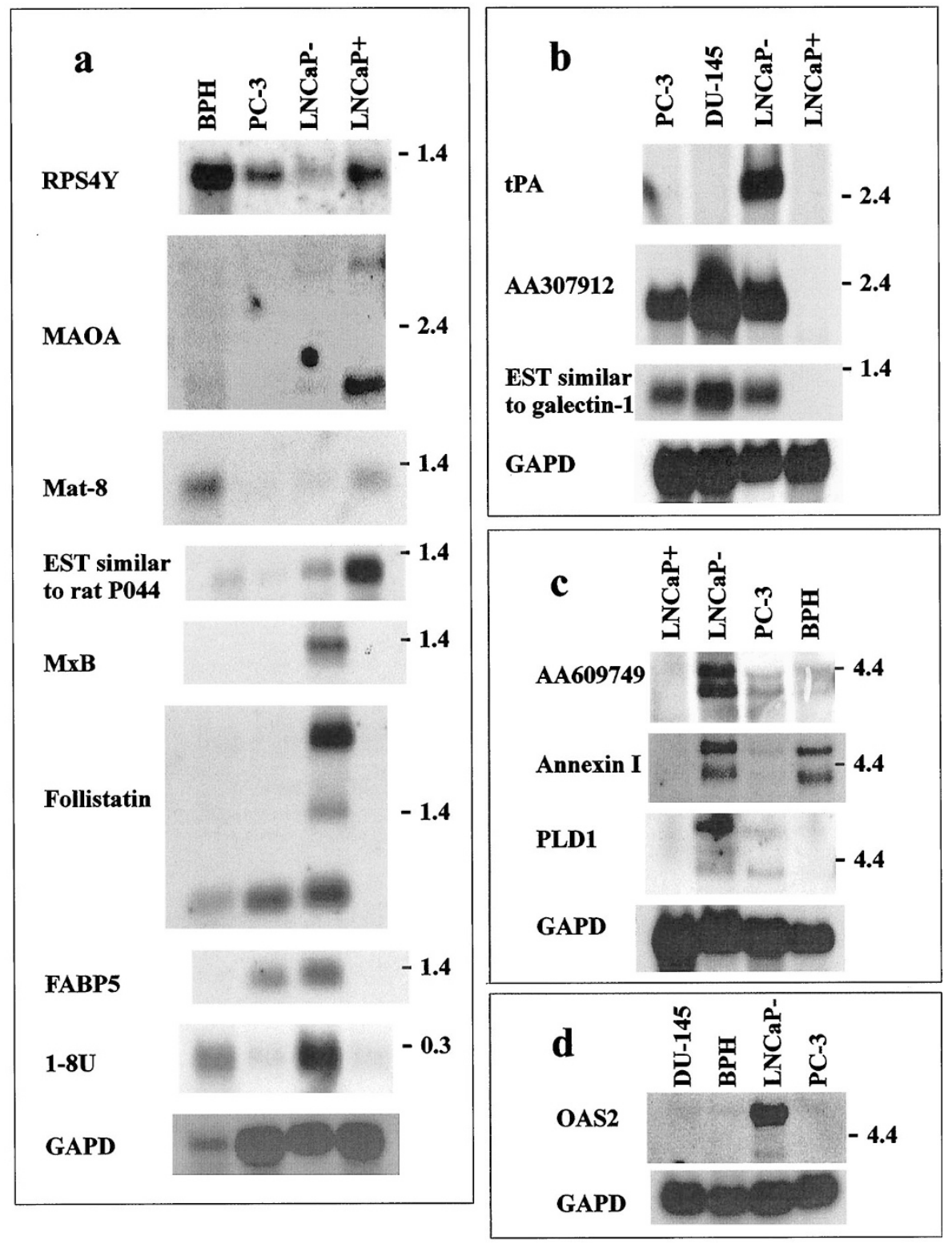

\section{Figure 1.}

Northern blot analysis of selected genes differentially expressed in LNCaP+/- cells according to cDNA array. a, Expression of Y-linked ribosomal protein S4 (RPS4Y), monoamine oxidase $\mathrm{A}(M A O A)$, Mat-8, expressed sequence tag (EST) similar to rat P044, MxB, follistatin, fatty acid-binding protein 5 (FABP5), interferon-inducible gene 1-8U (1-8U), and GAPD in BPH tissue, PC-3, LNCaP - , and LNCaP+ cells. $b$, Expression of tissue-type plasminogen activator (tPA), EST AA307912, EST similar to galectin-1, and GAPD in PC-3, DU-145, LNCaP-, and LNCaP + cells. c, Expression of EST AA609749, annexin I, phospholipase D1 (PLD1), and GAPD in LNCaP+ cells, LNCaP - cells, PC-3 cells, and BPH tissue. $d$, Expression of $2^{\prime}-5^{\prime}$ oligoadenylate synthetase 2 (OAS2) and GAPD in DU-145 cells, BPH tissue, LNCaP- cells, and PC-3 cells. RNA size markers are indicated on the right hand side. Five micrograms of mRNA was loaded on the gel in $a$ and $10 \mu \mathrm{g}$ in $b$ to $d$.

\section{Analysis of Overexpressed Genes in LNCaP- Cells}

In the prostate cell lines studied, tissue-type plasminogen activator (tPA) was expressed only in LNCaPcells; no expression was seen in BPH tissue (Table 4, Fig. 1b). MxB, like tPA, was expressed only in LNCaP - cells (Table 4, Fig. 1a). Expression of EST AA307912 was detected in the androgen-independent cell lines, DU-145 and PC-3, as well as in LNCaPcells (Fig. 1b). However, EST AA307912 was also expressed in $\mathrm{BPH}$ tissue (Table 4). The EST similar to galectin-1 was expressed most strongly in LNCaPcells (Table 4, Fig. 1b), otherwise, its expression pattern was comparable to that of EST AA307912. In previous studies, galectin-1 expression was observed only in androgen-independent DU-145, PC-3, and metastatic PC-3M cell lines (Ellerhorst et al, 1999a), similar to the expression pattern of the EST similar to galectin-1. In prostate tissue, the EST similar to galectin-1 was expressed in the stroma (Fig. 2, i and j), where the expression of galectin-1 has also been localized by immunohistochemistry (Ellerhorst et al, 1999b).

Follistatin and fatty acid-binding protein 5 (Table 4, Fig. 1a) were expressed in LNCaP- cells and in the 


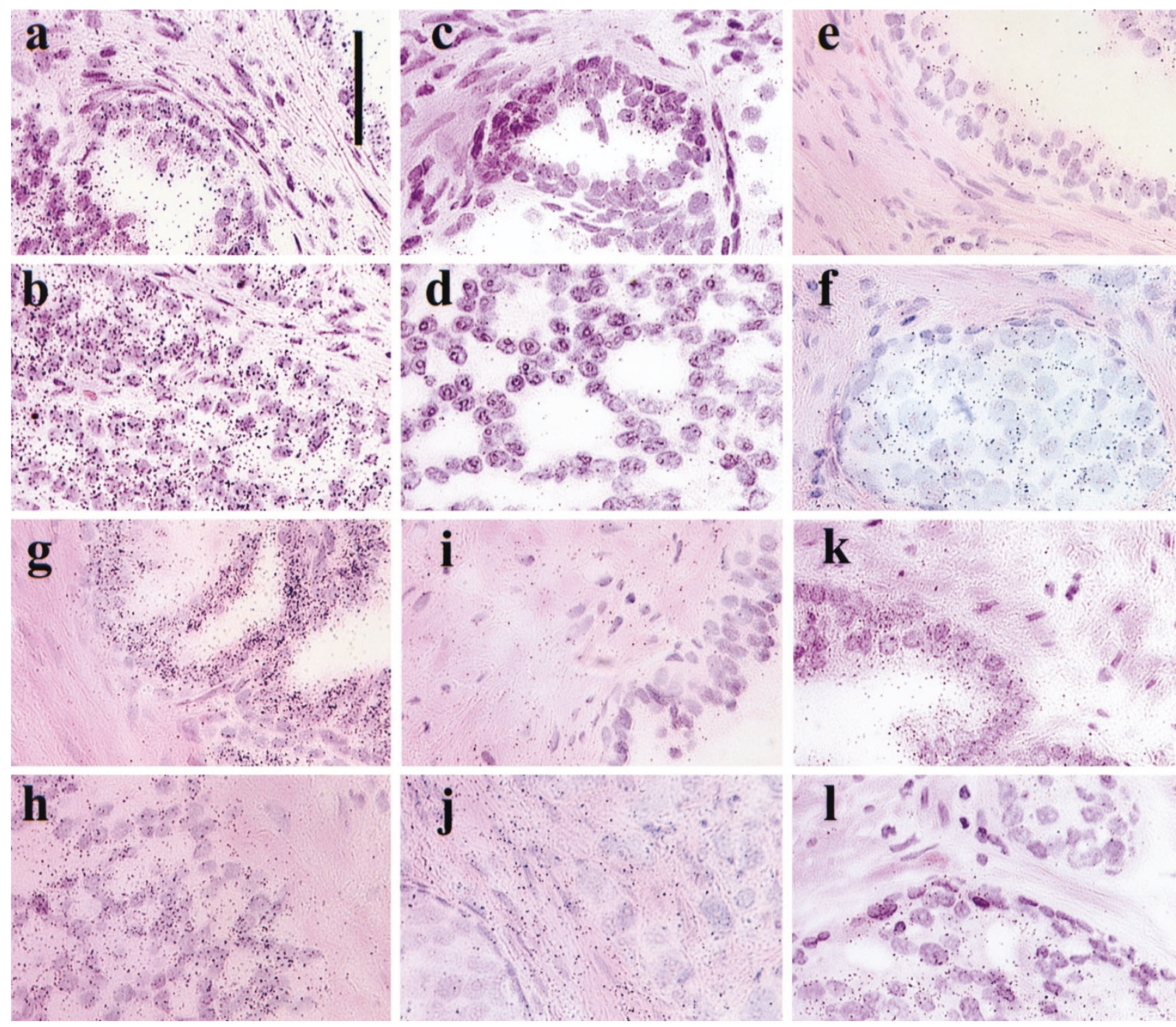

Figure 2.

In situ hybridization of overexpressed genes in LNCaP + and LNCaP - cells. MAOA, EST AA781244, and fatty acid-binding protein 5 were expressed in both benign $(a, e$, and $k$, respectively) and malignant ( $b, f$, and $I$, respectively) epithelium of human prostate. Expression of the EST similar to rat P044 was weak, but still detectable in epithelium of BPH (c) and prostate cancer (d). EST AA412049 tended to be slightly more highly expressed in benign epithelial cells $(g)$ compared with malignant epithelium $(h)$. The EST similar to galectin-1 was expressed in the stroma of both BPH and prostate cancer samples ( $i$ and $j$, respectively). Hematoxylin and eosin staining. Black vertical bar in right upper corner of a corresponds to $50 \mu \mathrm{m}$ for all panels.

androgen-independent PC-3 cell line. Several mRNA species for follistatin were detected in LNCaP- cells (Fig. 1a) and one was also expressed in BPH tissue. Fatty acid-binding protein 5 was expressed in both benign and malignant epithelium by ISH (Fig. 2, $\mathrm{k}$ and I), although it was not expressed in BPH tissue in Northern blot. EST AA609749 was most abundantly expressed in LNCaP - cells, weakly expressed in PC- 3 cells and BPH tissue, whereas the gene encoding this EST was silent in $\mathrm{LNCaP}+$ cells (Table 4, Fig. 1c).

Annexin I (Fig. 1C) and 1-8U (Fig. 1a) were expressed in both LNCaP - cells and BPH tissue (Table 4). Annexin I was also detectable in PC-3 cells. According to the results of $\mathrm{ISH}$, the expression of 1-8U was interesting (Fig. 3, a to e) because it was concentrated in some cells of cancer areas. In benign tissue, 1-8U was mainly localized in epithelial cells. However, in some areas, expression was also detected in the stroma. Phospho- lipase D1 was strongly expressed in $\mathrm{LNCaP}$ - cells and low amounts of mRNA were detected in PC-3 cells, whereas $\mathrm{LNCaP}+$ cells and $\mathrm{BPH}$ tissue totally lacked expression (Table 4, Fig. 1C).

According to the cDNA expression array analysis, OAS2 was 34.6 times overexpressed in LNCaP- cells (Table 3). In Northern blot (Fig. 1d), OAS2 transcripts were clearly observed only in LNCaP- cells, not in $\mathrm{BPH}$ tissue, DU-145, or PC-3 cell lines. In ISH, expression of OAS2 (Fig. 3, g and h) was detected in some prostate cancer areas in the samples analyzed. Expression was also seen in non-malignant prostate tissue, but the sparsely distributed transcript level was low.

\section{Discussion}

Here we describe the results of cDNA microarray screening of two LNCaP cell line variants. Sixteen 

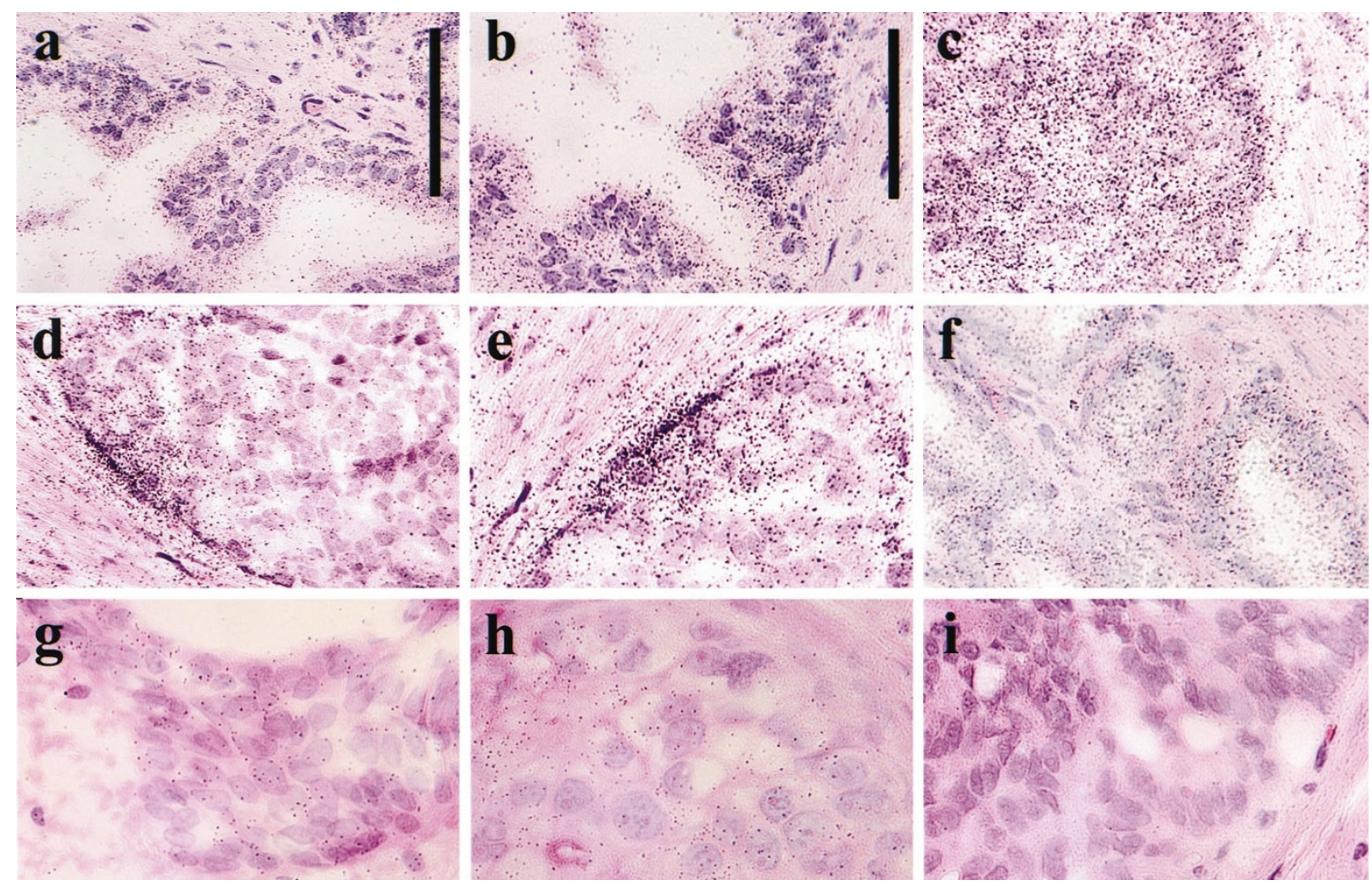

Figure 3 .

In situ hybridization results of overexpressed genes in LNCaP- cells. The interferon-inducible gene 1-8U was expressed in both benign $(a$ and $b$ ) and malignant ( $c$ ) epithelium. Expression was also detected in the stroma. Furthermore, the expression level varied within any one sample ( $d$ and $e$ ). $b$ and $e$ represent higher magnifications of $a$ and $d$, respectively. OAS2 was expressed in epithelia of BPH $(g)$ and prostate cancer $(h)$, but only in some of the samples analyzed. Hybridization with sense OAS2 probe gave no signal ( $I$ ). Preservation of RNA in the samples was confirmed by hybridization with GAPD probe $(f)$. Hematoxylin and eosin staining. Black vertical bars in right upper corners of $a$ and $b$ correspond to 100 and $50 \mu \mathrm{m}$, respectively. $d$ has same magnification as $a ; c, e, f, g, h$, and $i$ have same magnifications as $b$.

genes were selected from the array; differential expression of fourteen of these genes was confirmed by Northern blotting. Among differentially expressed genes, there are many potential prostate cancer markers. Several genes studied more closely here have previously been investigated with regards to their overall association with cancer. These genes are tPA, OAS, follistatin, annexin I, 1-8U, PSA, hK2, TMPRSS2, MAOA, and Mat-8. Of these, only PSA, hK2, TMPRSS2, tPA, and follistatin have been studied specifically in prostate cancer. Additionally, six EST clones or clones without a known product or function were found to be differentially expressed (EST similar to rat P044, AC: Al192351; EST similar to galectin-1, AC: AA340061; AC: AA781244; AC: AA412049; AC: AA307912; and AC: AA609749). Our results indicate that the well known androgen-regulated prostatic proteins PSA and hK2 are highly expressed in LNCaP+ cells, whereas they are down-regulated in LNCaPcells.

The galectins are a family of lectins that probably mediate cell adhesion, regulate cell growth, and trigger or inhibit apoptosis. The expression pattern of some galectins is altered in breast, colon, prostate, and thyroid carcinomas (Perillo et al, 1998). Our finding of overexpression of an EST similar to galectin-1 in LNCaP - cells suggests that these cells are trans- formed to a more progressive stage of prostate cancer compared with galectin-1, which was expressed in DU-145, PC-3, and PC-3M cells but not in LNCaP cells analyzed by Northern blotting and immunoblotting (Ellerhorst et al, 1999a). Furthermore, another protein sharing similarity with the galectin family, PCTA-1, is expressed in prostate cancer tissue (Su et al, 1996).

Overexpression of follistatin in LNCaP - cells is in accordance with the theory of follistatin overproduction favoring androgen-independent prostate cancer growth (Thomas et al, 1997). Activin inhibits the growth of DU-145 and LNCaP cells, even after androgen-stimulation (Wang et al, 1999), but not PC-3 cell lines. This inhibition may be prevented by follistatins (Thomas et al, 1997). An interesting question is how to overcome the growth-promoting influence of follistatin in prostate cancer cells.

MxA and MxB belong to the family of large GTPases. Cytoplasmic human MxA protein mediates resistance to multiple RNA viruses, whereas no antiviral activity has been found for human MxB protein (Melen et al, 1996). The genes for MxA and MxB are located in the same chromosomal area as the TMPRSS2 gene, 21q22.3 (Paoloni-Giacobino et al, 1997). Interestingly, $\mathrm{MxA}$ and $\mathrm{MxB}$ were up-regulated in the androgen-independent cell line ( $\mathrm{LNCaP}-)$, whereas 
TMPRSS2 was down-regulated in these cells. Thus, deletion of this chromosomal area is not likely to clarify the differential expression of these genes in the cell line variants, and up- or down-regulation is due to specific regulatory factors. Additionally, expression of TMPRSS2 is androgen-regulated (Lin et al, 1999; Vaarala et al, unpublished data) and low amounts of TMPRSS2 as well as other androgen-dependent serine proteases in $\mathrm{LNCaP}$ - cells reflect a change in the hormonal status/response of this cell line variant.

The antitumor effectiveness of interferons in vivo and in vitro is well documented. OAS is an interferoninducible enzyme that polymerizes $2{ }^{\prime}-5$ ' oligoadenylates from adenosine triphosphate. 2'-5' oligoadenylates, in turn, are responsible for RNaseL activation, which is needed for RNA degradation and antiviral action (Stryer, 1988). However, only some of the interferon-inducible genes activated in LNCaP - cells are known to belong to the OAS-RNaseL pathway. The uneven distribution of OAS2 mRNA in prostate samples found here may reflect participation in cell growth regulation or an as yet unknown process involved in the development of cancer cell populations with different endocrine characteristics. The cytocidal effect of treating the HT29 human colon carcinoma cell line with both TNF- $\alpha$ and interferon- $\gamma$ is reported to be accompanied by an increase in OAS levels and apparent rRNA breakdown (Chapekar and Glazer, 1988). However, the antiproliferative effects of interferons did not correlate with induction of OAS in human lung cancer (Martyre et al, 1988). The gene encoding 1-8U has been observed to be strongly expressed in ulcerative colitis-associated colon cancers (Hisamatsu et al, 1999). This gene is highly interferon-inducible, but its function is unclear. There is some evidence of a link between prostate cancer and colon cancer (Moore et al, 1998) and, furthermore, the expression of certain genes is similarly altered in cancers of different tissues (eg, KAl1). It is therefore possible that 1-8U also has some association with prostate cancer. The activation of interferon-inducible genes in LNCaP - cells seems to be involved in the transition to more aggressive growth or malignant transformation, as in the case of 1-8U in colon cancer (Hisamatsu et al, 1999). The possibility of this induction being a result of mycoplasma contamination was ruled out by regular testing of the cells.

Mat-8 is an 8-kd transmembrane protein homologous to phospholemman (Morrison et al, 1995). It is differentially expressed in the MCF-7 breast cancer cell line and in a progressive variant of MCF-7 (Schiemann et al, 1998). The kallikrein gene family and Mat-8 genes are located in chromosomal region 19q, suggesting that this genetic area could be vulnerable to regulatory changes during transformation.

The Y-linked ribosomal protein S4 was most prominently expressed in BPH tissue and was also detectable in LNCaP + cells. The gene encoding this protein is overexpressed in a non-metastatic variant of rat rhabdomyosarcoma, SMF-Da (Daigneault et al, 1995). The expression of several other ribosomal proteins is also altered in prostate cancer and prostate cancer cell lines (Vaarala et al, 1998).

Angiostatin, an inhibitor of angiogenesis and growth of tumor metastases, is generated by urokinasemediated proteolysis of plasminogen in the PC-3 cell line (Gately et al, 1997). Recently, PSA has also been shown to have antiangiogenic activity (Fortier et al, 1999). Another plasminogen activator, tPA, was overexpressed in LNCaP - cells. Down-regulation of PSA production possibly leads to accumulation of plasminogen in these cells, which might then promote upregulation of the gene encoding tPA. However, according to Gately et al, 1997, tPA seems not to have similar activity to urokinase and PSA (Fortier et al, 1999), and the concentration of tPA is not altered in prostate cancer tissue compared with normal prostate tissue (Plas et al, 1998). Unfortunately, cDNA for urokinase was not available in the array. The plasminogen gene was expressed at a low level with signal values of 575 and 281 in LNCaP + and LNCaP - cells, respectively.

Several electronic databanks now offer tissue- or cell line-specific expression data for cDNA clones. A sophisticated model for expression studies in prostate tissue specimens, using the microarray technique, has been presented recently (Cole et al, 1999). Information given by cDNA arrays, as in the present study, is a valuable tool in cancer research, because genes with prominent or very low expression can be compared with expression data available on another disease states. For example, finding a gene with high expression in LNCaP + and LNCaP - cells, with no or low expression in $\mathrm{BPH}$ or normal prostate tissue, would reveal a potential new prostate cancer marker. Careful examination of clones is still needed, because there are differences within and between LNCaP cell lines and prostate cancer, as indicated by ISH analyses.

\section{Materials and Methods}

\section{Cells and Tissues}

LNCaP-FGC, PC-3, and DU-145 cells were purchased from ATCC (Rockville, Maryland). Production of PSA by LNCaP cells was followed by using DELFIA PSA kits (Wallac, Turku, Finland); cell clone variants with high PSA production and undetectable PSA production were selected. Lack of mycoplasma contamination was confirmed regularly (Gen-Probe, San Diego, California). Tissues for ISH were taken from prostatic adenocarcinoma patients treated by radical prostatectomy or transurethral electroresection of the prostate. BPH tissue was obtained from patients treated by radical/total prostatectomy. These treatments are widely used and accepted in cases of BPH and prostate cancer. Tissues were removed only for treatment purposes and were used for this study only after diagnostic confirmation by histopathology.

\section{RNA Isolation, cDNA Microarray, and Clone Sequencing}

Total RNA was isolated from the cells using TRIzol (Life Technologies, Gaithersburg, Maryland). Poly-A 
RNA was isolated using a QuickPrep Micro mRNA Purification Kit (AmershamPharmacia, Uppsala, Sweden). mRNA was used for Human UniGEM V v1.0 Custom Screening (GenomeSystems Inc., St. Louis, Missouri). mRNAs from LNCaP $+/$ - cells were labeled with different fluorescent labels. Average signals for the elements in the array were achieved for both probes. For details of screening and clone selection, see http://www.genomesystems.com. Results are presented as either probe average signal values (arbitrary units) or as overexpression, when signal values of a cell line are divided by signal values in the other cell line. Histologically confirmed tissue samples of $\mathrm{BPH}$ were used for the isolation of total RNA by the $\mathrm{CsCl}$ gradient method. Poly-A RNA was isolated using oligo(dT)-cellulose (AmershamPharmacia) and standard methods. Clones selected according to screening were purchased from GenomeSystems Inc. and were further sequenced using an ABI377 automatic sequencer (Applied Biosystems, Branchburg, New Jersey) to confirm the sequence data and clone orientation.

\section{Northern Blot Analysis}

mRNA isolated from the cells and tissues were loaded on the gel. Northern blots were carried out as recommended by the membrane manufacturer (Boehringer Mannheim, Mannheim, Germany). Hybridization was carried out with ${ }^{32} \mathrm{P}$-labeled cDNA and GAPD in plasmid vectors. The filters were washed under high stringency conditions and exposed to Kodak MS film (Eastman Kodak, Rochester, New York) with intensifying screens. The filters were stripped and removal of probes was confirmed by exposure of the blots before each hybridization.

\section{In Situ Hybridization}

Antisense and sense $\left[\alpha^{-}{ }^{35}\right.$ S $]$ CTP-labeled RNA probes were transcribed with T7 or SP6 RNA polymerases using linearized plasmids as templates. The specific activities of the synthesized RNA probes were approximately $6 \times 10^{6} \mathrm{cpm} / \mu \mathrm{l}$. ISH was carried out as previously described (Mustonen et al, 1998) using tissue samples obtained from transurethral electroresection of prostate cancer patients and tissue blocks containing BPH tissue and prostate cancer tissue. The hybridization temperature was $60^{\circ} \mathrm{C}$. The slides were stained with hematoxylin and eosin, and mounted with Pertex (Histolab, Göteborg, Sweden). Each probe was analyzed in a minimum of two BPH tissue samples and two prostate cancer samples.

\section{Acknowledgements}

We are grateful to Ms. Helmi Konola and Ms. Mirja Mäkeläinen for technical assistance.

\section{References}

Bussemakers MJ, van Bokhoven A, Verhaegh GW, Smit FP, Karthaus HF, Schalken JA, Debruyne FM, Ru N, and
Isaacs WB (1999). DD3: A new prostate-specific gene, highly overexpressed in prostate cancer. Cancer Res 59:5975-5979.

Chang GT, Blok LJ, Steenbeek M, Veldscholte J, van Weerden WM, van Steenbrugge GJ, and Brinkmann AO (1997). Differentially expressed genes in androgen-dependent and -independent prostate carcinomas. Cancer Res 57:40754081.

Chapekar MS and Glazer RI (1988). The synergistic cytocidal effect produced by immune interferon and tumor necrosis factor in HT-29 cells is associated with inhibition of rRNA processing and $\left(2^{\prime}, 5^{\prime}\right)$ oligo $(A)$ activation of RNase $L$. Biochem Biophys Res Commun 151:1180-1187.

Cole KA, Krizman DB, and Emmert-Buck MR (1999). The genetics of cancer -a 3D model. Nat Genet 21:38-41.

Daigneault L, Beaulieu R, Filion M, Gaboury L, Royal A, and Babai $F$ (1995). Cloning and identification of genes differentially expressed in metastatic and non-metastatic rat rhabdomyosarcoma cell lines. Clin Exp Metastasis 13:345-356.

Ellerhorst J, Nguyen T, Cooper DN, Lotan D, and Lotan R (1999a). Differential expression of endogenous galectin-1 and galectin- 3 in human prostate cancer cell lines and effects of overexpressing galectin-1 on cell phenotype. Int J Oncol 14:217-224.

Ellerhorst J, Troncoso P, Xu XC, Lee J, and Lotan R (1999b). Galectin-1 and galectin-3 expression in human prostate tissue and prostate cancer. Urol Res 27:362-367.

Fearon ER and Vogelstein B (1990). A genetic model for colorectal tumorigenesis. Cell 61:759-767.

Fortier AH, Nelson BJ, Grella DK, and Holaday JW (1999). Antiangiogenic activity of prostate-specific antigen. $\mathrm{J}$ Natl Cancer Inst 91:1635-1640.

Gately S, Twardowski P, Stack MS, Cundiff DL, Grella D, Castellino FJ, Enghild J, Kwaan HC, Lee F, Kramer RA, Volpert O, Bouck N, and Soff GA (1997). The mechanism of cancer-mediated conversion of plasminogen to the angiogenesis inhibitor angiostatin. Proc Natl Acad Sci U S A 94:10868-10872.

Hisamatsu T, Watanabe M, Ogata H, Ezaki T, Hozawa S, Ishii $\mathrm{H}$, Kanai T, and Hibi T (1999). Interferon-inducible gene family 1-8U expression in colitis-associated colon cancer and severely inflamed mucosa in ulcerative colitis. Cancer Res 59:5927-5931.

Horoszewicz JS, Leong SS, Chu TM, Wajsman ZL, Friedman M, Papsidero L, Kim U, Chai LS, Kakati S, Arya SK, and Sandberg AA (1980). The LNCaP cell line —a new model for studies on human prostatic carcinoma. Prog Clin Biol Res 37:115-132.

Knudson AG (1993). All in the (cancer) family. Nat Genet 5:103-104.

Lin BY, Ferguson C, White JT, Wang S, Vessella R, True LD, Hood L, and Nelson PS (1999). Prostate-localized and androgen-regulated expression of the membrane-bound serine protease TMPRSS2. Cancer Research 59:4180-4184.

Martyre MC, Beaupain R, and Falcoff E (1988). Human lung cancer nodules in organotypic culture: No evidence of correlation between the antiproliferative effects of interferons and the induction of $2^{\prime}, 5^{\prime}$-oligoadenylate synthetase. Tumour Biol 9:263-269. 
Melen K, Keskinen P, Ronni T, Sareneva T, Lounatmaa K, and Julkunen I (1996). Human MxB protein, an interferonalpha-inducible GTPase, contains a nuclear targeting signal and is localized in the heterochromatin region beneath the nuclear envelope. J Biol Chem 271:23478-23486.

Moore MA, Kunimoto T, Park CB, Takasuka N, and Tsuda H (1998). European country comparisons provide evidence of a link between colon cancer and adenocarcinoma development in the lung but not the oesophagus. Eur $\mathrm{J}$ Cancer Prev 7:473-478.

Morrison BW, Moorman JR, Kowdley GC, Kobayashi YM, Jones LR, and Leder P (1995). Mat-8, a novel phospholemman-like protein expressed in human breast tumors, induces a protein conductance in Xenopus oocytes. J Biol Chem 270:2176-2182.

Mustonen MVJ, Poutanen MH, Kellokumpu S, de Launoit $\mathrm{Y}$, Isomaa VV, Vihko RK, and Vihko PT (1998). Mouse 17 beta-hydroxysteroid dehydrogenase type $2 \mathrm{mRNA}$ is predominantly expressed in hepatocytes and in surface epithelial cells of the gastrointestinal and urinary tracts. J Mol Endocrinol 20:67-74.

Paoloni-Giacobino A, Chen H, Peitsch MC, Rossier C, and Antonarakis SE (1997). Cloning of the TMPRSS2 gene, which encodes a novel serine protease with transmembrane, LDLRA, and SRCR domains and maps to 21q22.3. Genomics 44:309-320.

Perillo NL, Marcus ME, and Baum LG (1998). Galectins: Versatile modulators of cell adhesion, cell proliferation, and cell death. J Mol Med 76:402-412.

Plas E, Carroll VA, Jilch R, Mihaly J, Vesely M, Ulrich W, Pfluger H, and Binder BR (1998). Analysis of fibrinolytic proteins in relation to DNA ploidy in prostate cancer. Int $\mathrm{J}$ Cancer 78:320-325.

Schiemann S, Schwirzke M, Brunner N, and Weidle UH (1998). Molecular analysis of two mammary carcinoma cell lines at the transcriptional level as a model system for progression of breast cancer. Clin Exp Metastasis 16:129139.
Schroder FH (1998). Endocrine treatment of prostate cancer. In: Walsh PC, Retik AB, Vaughan ED, and Wein AJ, editors. Campbell's urology. Philadelphia: WB Saunders, 2627-2644.

Stryer L (1988). Viruses and oncogenes. In: Stryer L, editor. Biochemistry. New York: WH Freeman and Company, 851885.

Stubbs AP, Abel PD, Golding M, Bhangal G, Wang Q, Waxman J, Stamp GW, and Lalani EN (1999). Differentially expressed genes in hormone refractory prostate cancer: Association with chromosomal regions involved with genetic aberrations. Am J Pathol 154:1335-1343.

Su ZZ, Lin J, Shen R, Fisher PE, Goldstein NI, and Fisher PB (1996). Surface-epitope masking and expression cloning identifies the human prostate carcinoma tumor antigen gene PCTA-1 a member of the galectin gene family. Proc Natl Acad Sci U S A 93:7252-7257.

Thomas TZ, Wang H, Niclasen P, O'Bryan MK, Evans LW, Groome NP, Pedersen J, and Risbridger GP (1997). Expression and localization of activin subunits and follistatins in tissues from men with high grade prostate cancer. J Clin Endocrinol Metab 82:3851-3858.

Vaarala MH, Porvari KS, Kyllonen AP, Mustonen MV, Lukkarinen O, and Vihko PT (1998). Several genes encoding ribosomal proteins are over-expressed in prostate-cancer cell lines: Confirmation of L7a and L37 over-expression in prostate-cancer tissue samples. Int J Cancer 78:27-32.

van Steenbrugge GJ, van Uffelen CJ, Bolt J, and Schroder FH (1991). The human prostatic cancer cell line LNCaP and its derived sublines: An in vitro model for the study of androgen sensitivity. J Steroid Biochem Mol Biol 40:207214.

Wang Q, Tabatabaei S, Planz B, LIn CW, and Sluss PM (1999). Identification of an activin-follistatin growth modulatory system in the human prostate: Secretion and biological activity in primary cultures of prostatic epithelial cells. J Urol 161:1378-1384. 